\title{
List of Reviewers Vol. 159, No. 2-3, 1997
}

Botterman, B.R., Dallas, Tex., USA

Caiozzo, V.J., Irvine, Calif., USA

Grossman, E.J., Los Angeles, Calif., USA

Hermanson, J.W., Ithaca, N.Y., USA Herring, S.W., Seattle, Wash., USA

Ishihara, A., Kyoto, Japan

Lieber, R.L., San Diego, Calif., USA Monti, R.J., Los Angeles, Calif., USA Pierotti, D.J., Flagstaff, Ariz., USA Roy, R.R., Los Angeles, Calif., USA Trotter, J., Albuquerque, N.Mex., USA 